\title{
Biphasic insulin aspart 30/70 (BIAsp 30) in the treatment of type I and type 2 diabetes
}

This article was published in the following Dove Press journal:

Diabetes, Metabolic Syndrome and Obesity:Targets and Therapy

3 June 2009

Number of times this article has been viewed

\section{Paul Valensi}

Department of EndocrinologyDiabetology-Nutrition, Jean Verdier Hospital, AP-HP, Paris Nord University, CRNH-IdF, Bondy, France
Correspondence: P Valensi Service d'Endocrinologie-DiabétologieNutrition, Hôpital Jean Verdier, Avenue du 14 Juillet, 93।43, Bondy Cedex, France Tel +33 I 48026597

Fax +33 I 48026356

Email paul.valensi@jvr.aphp.fr
Abstract: The pharmacological advantages of the rapid-acting analog, insulin aspart, over human insulin have contributed to the widespread prescription of the premix, biphasic insulin aspart 30/70 (BIAsp 30), in type 1 (T1DM) and type 2 diabetes (T2DM). This article reviews the available literature on the pharmacology, efficacy and safety of BIAsp 30 in T1DM and T2DM from an online search of the PubMed database. Following injection, BIAsp 30 reaches higher plasma insulin levels more quickly than human premix or basal insulin, giving effective reduction of postprandial hyperglycemia. In T1DM patients, randomized controlled trials (RCTs) have shown that $\mathrm{HbA}_{1 \mathrm{c}}$ reduction is similar, but postprandial glycemic control is better, with BIAsp 30 than with human insulin regimens. In T2DM patients, lowering of $\mathrm{HbA}_{1 \mathrm{c}}$ and postprandial hyperglycemia with BIAsp 30 compare favorably with optimized oral antidiabetes drug treatment, insulin glargine, and, in obese patients, human premix. An increase in minor hypoglycemia with BIAsp 30 relative to basal insulin has been reported in T2DM patients, but major and nocturnal hypoglycemia rates are generally low. Findings from RCTs in T2DM patients are supported by large observational studies. In summary, BIAsp 30 once to three times daily represents a simple and effective tool for the modern management of diabetes.

Keywords: biphasic insulin aspart, BIAsp 30, premix, type 1 diabetes, type 2 diabetes

\section{Introduction}

Diabetes mellitus is a global problem and the number of people being diagnosed is increasing rapidly. In 2000, the global prevalence of diabetes (type 1 and type 2 combined - epidemiological reports do not generally distinguish between them) was estimated to be $2.8 \%$ - a total of 171 million people, which is forecast to more than double by 2030 , to 366 million. ${ }^{1}$ This growth in diabetes is fuelled by increasing obesity, associated with high-calorie diets in developed countries and the modern sedentary lifestyle. The growing population is also a factor, with the largest change predicted to occur in the over 65 years age group. ${ }^{1}$ Since the prevalence of type 2 diabetes - the most frequently occurring type - increases with age, increase of the older population represents a major challenge for diabetes care in the future. The burden arises not just from the need to treat symptoms, but also the complications associated with hyperglycemia. ${ }^{2-4}$ The cost to society is therefore enormous. ${ }^{5,6}$

Given the extent of the problem, it is more important than ever that treatment of diabetes is as effective as possible. Recent baseline observational data from several countries/regions has shown that glycemic control in the type 2 diabetes population is generally poor, with mean glycated hemoglobin $\mathrm{A}_{1 \mathrm{c}}\left(\mathrm{HbA}_{1 \mathrm{c}}\right)$ levels of $9 \%$ or higher. ${ }^{7}$ This illustrates the need for treatment to be target-driven so that patients do 
not spend extended periods of time with hyperglycemia. Diabetes therapy should be intensified early and persistently, to keep pace with the progression of the disease. ${ }^{8}$ Adding insulin to the treatment regimen early is a key factor in good diabetes management since insulin is the most effective agent at reducing glycemia and doses can be titrated to target. ${ }^{9}$ Indeed, the International Diabetes Federation guidelines recommend adding insulin if $\mathrm{HbA}_{1 \mathrm{c}}>7.5 \% .{ }^{9}$ Timely intensification of insulin therapy should then follow. The potential benefits for complications are clear. The UKPDS study demonstrated that every $1 \%$ reduction in $\mathrm{HbA}_{1 \mathrm{c}}$ was associated with a $21 \%$ reduction in risk for any diabetesrelated endpoint. ${ }^{10}$

The pathophysiology of type 1 diabetes is different to that of type 2, so insulin needs after diagnosis are different. Patients with type 1 diabetes usually have little or no endogenous insulin capacity remaining - the result of autoimmune destruction of the pancreatic beta-cells. ${ }^{11}$ Patients therefore require immediate and often complete insulin replacement. Among the treatment options are continuous subcutaneous insulin infusion (CSII) and multiple daily injections (MDI). ${ }^{12}$ Although CSII is regarded as the 'gold standard' in insulin replacement in type 1 diabetes, ${ }^{13,14} \mathrm{MDI}$ is the most common method of insulin delivery, which may comprise four or five daily injections of separate basal and prandial insulin, usually referred to as basal-bolus therapy.

Patients with type 2 diabetes have different insulin needs initially from those with type 1 diabetes, due to different etiology. Here, insulin resistance - often linked to obesity - puts undue stress on the insulin-producing beta-cells, which eventually are unable to produce enough insulin to maintain normo-glycemia. ${ }^{15}$ The resulting glucose toxicity causes the death of beta-cells, thus reducing overall insulin-producing capacity. ${ }^{16,17}$ At the point of diagnosis, patients typically have about $50 \%$ of their insulin-producing capacity remaining. ${ }^{18,19}$

Initial treatment steps are therefore somewhat different to those for type 1 diabetes. After the failure of lifestyle changes, ${ }^{20}$ an oral antidiabetes drug (OAD) is usually the first-line therapy, but the benefits may be relatively shortlived. The UKPDS study found that three in four patients with type 2 diabetes were unable to maintain glycemic control with monotherapy 9 years after diagnosis. ${ }^{21,22}$ Initiating insulin therapy is the solution for many patients. In the advanced stages of type 2 diabetes when there is little or no endogenous insulin production, treatment requirements are essentially the same as those for patients with type 1 diabetes, that is, complete insulin replacement.
Insulin therapy may be initiated with basal insulin only, prandial (bolus) insulin only, or a premixed insulin comprising both prandial and basal components in each injection (a basal-bolus regimen of four or five daily injections would usually be deemed too intensive for most patients starting insulin therapy). Each has their advantages and disadvantages: basal-only insulin does not provide for mealtime requirements and bolus insulin does not provide for fasting insulin requirements. The premixed insulins offer a good alternative as they address both fasting and postprandial glycemia. ${ }^{23}$

Over the last decade or so, insulin therapy has been revolutionized by the development of insulin analogs. These are chemically modified versions of human insulin which, via recombinant DNA technology, have changes in the amino acid sequence which give them more physiological pharmacokinetics when absorbed from a subcutaneous depot, compared with injected human insulin. There are rapid-acting analogs to control postprandial glycemia: insulin aspart (NovoRapid ${ }^{\circledR}$; Novo Nordisk A/S, Denmark), insulin lispro (Humalog ${ }^{\circledR}$; Eli Lilly, USA) and insulin glulisine (Apidra ${ }^{\circledR}$; Sanofi-Aventis, France); and basal analogs for fasting glycemia: insulin detemir (Levemir $^{\circledR}$; Novo Nordisk A/S, Denmark) and insulin glargine (Lantus ${ }^{\circledR}$; Sanofi-Aventis, France).

Insulin aspart has been incorporated into a premix formulation: biphasic insulin aspart 30/70 (BIAsp 30), comprising 30\% rapid-acting, soluble, aspart for prandial coverage and $70 \%$ intermediate-acting, protaminated aspart, for basal coverage. The pharmacokinetics of aspart alone ${ }^{24,25}$ are retained when incorporated into the premix. ${ }^{26}$ BIAsp 30 can be injected from once (od) to three times (tid) daily in patients with type 2 diabetes, depending on their requirements, and tid in patients with type 1 diabetes. BIAsp 30 tid thus represents an alternative to basal-bolus therapy with fewer daily injections.

Because of these advantages, BIAsp 30 has become a widespread and commonly-prescribed treatment for patients with diabetes. The aim of this article is to review the use of BIAsp 30 in the treatment of type 1 and type 2 diabetes by examining the available literature. In so doing, I will compare its pharmacology, efficacy and safety profile with that of other insulins and establish the role of BIAsp 30 in diabetes management.

\section{Methods}

A literature search was carried out in January 2009 using the online database PubMed (www.pubmed.com/), for articles on the clinical use of BIAsp 30 using combinations of the following search terms: 'aspart,' 'biphasic insulin aspart,' 
'BIAsp,' 'pathophysiology,' 'pharmacokinetics,' 'pharmacodynamics,' 'type 1 diabetes' and 'type 2 diabetes' among others. The articles identified were then screened for content and relevance.

\section{BIAsp 30 pharmacology}

The improved pharmacology of BIAsp 30 compared with human insulin and basal analog insulin has been the key to its success as a therapy for type 1 and type 2 diabetes. When compared with human premix (biphasic human insulin 30/70 or BHI 30) in a single-injection study involving 24 healthy male volunteers, BIAsp 30 was found to reach $80 \%$ higher peak serum insulin levels $(23.4 \pm 5.3$ vs $15.5 \pm 3.7 \mathrm{mU} / \mathrm{L}, \mathrm{p}<0.0001)$ in approximately half of the time (median [range]: 60 [45-70] vs 110 [90-180] minutes, $\mathrm{p}=0.0001$ ), following a subcutaneous injection of $0.2 \mathrm{U} / \mathrm{kg}$ body weight (Figure 1). ${ }^{27}$ Thus, over the first 90 minutes postinjection, the area-under-the insulin/ time curve (AUC 0-90 min) - a measure of bioavailability was significantly higher for BIAsp 30 compared with BHI 30 (estimated ratio 1.85, $\mathrm{p}<0.0001$ ).

The pharmacodynamics (PD), or glucose-lowering effects, of the premixes reflected the pharmacokinetics (PK). The more rapid absorption of BIAsp 30 compared with BHI 30 resulted in a greater and more rapid reduction in serum glucose. Over the first 6 hours postinjection, the lowest serum glucose measured was $3.2 \pm 0.5$ and $3.7 \pm 0.5 \mathrm{mmol} / \mathrm{L}$, respectively $(\mathrm{p}<0.0001)$, reached in 70 (range $70-80)$ and $180(100-300)$ minutes, respectively $(\mathrm{p}=0.0001)$.

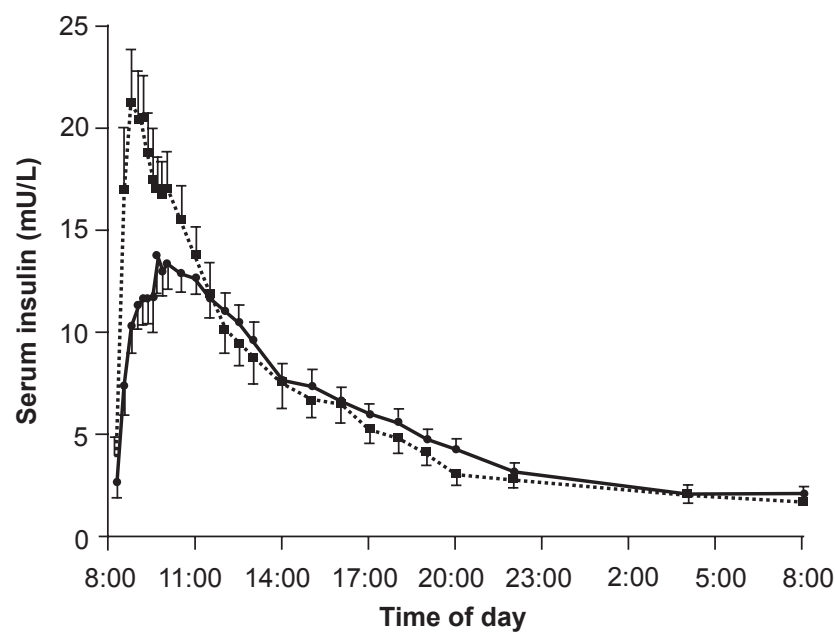

Figure I Mean pharmacokinetic profiles (serum insulin) over 24 hours after subcutaneous injections of $0.2 \mathrm{U} / \mathrm{kg}$ biphasic insulin aspart 30/70 (BIAsp 30 - solid squares) or biphasic human insulin 30/70 (BHI 30 - solid circles) in healthy volunteers. Reproduced with permission from Jacobsen LV,Sogaard B and Riis A. Pharmacokinetics and pharmacodynamics of a premixed formulation of soluble and protamine-retarded insulin aspart. Eur J Clin Pharmacol. 2000;56:399-403. ${ }^{27}$ Copyright @ Springer Science and Business Media.
These differences between BIAsp 30 and BHI 30 have also been noted in patients with type 2 diabetes. ${ }^{28,29}$ In one crossover study, 24-hour PK and PD profiles were recorded after patients had received BIAsp 30 twice daily (bid) for 2 weeks, and again after receiving BHI 30 for a further 2 weeks. $^{28}$

After each treatment period, maximum serum insulin levels and $\mathrm{AUC}_{\text {insulin }} 0$ to 2 hours after breakfast and dinner were significantly higher with BIAsp 30 than with BHI 30 (both $\mathrm{p}<0.05$ ), with a shorter time to maximum level. Furthermore, serum glucose excursions were significantly lower after breakfast and dinner with the BIAsp 30 regimen (breakfast: $14.0 \pm 5.5 \mathrm{vs} 23.6 \pm 5.5 \mathrm{mmol} \cdot \mathrm{L}^{-1} \cdot \mathrm{h}^{-1}, \mathrm{p}<0.05$; dinner: $9.1 \pm 5.9$ vs $\left.13.0 \pm 6.4 \mathrm{mmol} \cdot \mathrm{L}^{-1} \cdot \mathrm{h}^{-1}, \mathrm{p}<0.05\right)$, although significantly higher after lunch compared with BHI $30\left(25.4 \pm 11\right.$ vs $\left.16.9 \pm 8.5 \mathrm{mmol} \cdot \mathrm{L}^{-1} \cdot \mathrm{h}^{-1}, \mathrm{p}<0.05\right) .{ }^{28} \mathrm{No}$ doubt this is due to the soluble human insulin having a longer duration of action than insulin aspart following the breakfast injection, so there was more carry-over of metabolic effect at lunchtime with BHI 30.

It is not surprising that pharmacological advantages have also been demonstrated over the basal insulin analog, insulin glargine, since this insulin does not have a prandial, rapid-acting component. In the crossover glucose-clamp study by Luzio et $\mathrm{al}^{30} 12$ insulin-naive patients with type 2 diabetes received two injections of BIAsp $30(0.25 \mathrm{U} / \mathrm{kg}$ at 08.30 hours and $0.25 \mathrm{U} / \mathrm{kg}$ at 20.30 hours) on one day, and a single injection of glargine $(0.5 \mathrm{U} / \mathrm{kg}$ at 08.30 hours $)$ on another (the total daily insulin dose was therefore the same for the two treatments). Plasma glucose was clamped at a set level, and plasma insulin and glucose infusion rate (GIR - the amount of glucose needed to maintain the clamp level following the insulin injections) were measured for 24 hours. Maximum insulin concentration $\left(\mathrm{C}_{\max }\right)$ was higher for BIAsp 30 than for glargine, due to the rapidly-absorbed aspart peaks following injection, as expected, and interestingly the insulin AUC 0-24 hour was 28\% larger for BIAsp $30(\mathrm{p}=0.001)$, demonstrating greater bioavailability at the same total daily dose. Consequently, the GIR AUC 0-24 hours was 35\% higher for BIAsp 30 than for glargine, indicating greater glucose-lowering power dose-for-dose. ${ }^{30}$

\section{Efficacy of BIAsp 30 Type I diabetes}

\section{Glycated hemoglobin Alc $\left(\mathrm{HbA}_{\mid c}\right)$}

The use of BIAsp 30 in the type 1 diabetes patient population is not as common as it is in the type 2 population. This is partly because there are many more patients with type 2 
diabetes, and partly because there is the need to provide complete insulin replacement in patients with type 1 diabetes, so pump therapy and basal-bolus - still widely regarded as the gold standard - are more popular than premix insulin analog therapy. Consequently, the number of studies of BIAsp 30 in people with type 1 diabetes is rather limited. ${ }^{31-33}$ Comparing results from these trials is not straightforward because they employed different designs and comparators. However, some generalizations can be made. Three of these four studies measured the percentage of $\mathrm{HbA}_{1 \mathrm{c}}\left(\% \mathrm{HbA}_{1 \mathrm{c}}\right)$ to assess overall glycemic control and in all cases, no significant differences were found with respect to the comparator human insulin - either BHI 30 or soluble human insulin/NPH insulin. Specifically, in the 24-week crossover study by Chen et $\mathrm{al}^{32}$ involving 23 type 1 patients, BIAsp 30 tid (before all main meals) was compared with basal-bolus therapy comprising soluble human insulin tid plus human NPH insulin at bedtime. NPH insulin was added at bedtime to the BIAsp 30 regimen for those patients who needed it. At the end of the study, $\mathrm{HbA}_{1 \mathrm{c}}$ had dropped from $9.1 \%$ to $8.5 \%$ for both insulin regimens (in the 12 patients who did not receive additional NPH insulin). These $\mathrm{HbA}_{1 \mathrm{c}}$ values were significant improvements from baseline $(\mathrm{p}<0.05)$ for both regimens, achieved with the same total daily dose of 50 (I)U/day.

Results in young people have been more modest. In the 16-week, parallel-group trial of 167 adolescents with type 1 diabetes aged 10 to 17 years, BIAsp 30 tid was compared with BHI 30 at breakfast plus soluble human insulin at lunch and dinner. ${ }^{31}$ During the study, $\mathrm{HbA}_{1 \mathrm{c}}$ was reduced from $9.70 \pm 1.52 \%$ at baseline to $9.39 \pm 0.14 \%$ at final visit in the BIAsp 30 group, and from $9.55 \pm 1.59 \%$ to $9.30 \pm 0.15 \%$ in the human insulin group. Reductions were clearly very small and differences between treatments were not significant.

The last of these studies to report $\mathrm{HbA}_{1 \mathrm{c}}$ is the 12 -week parallel group trial of patients already using twice-daily insulin therapy ${ }^{34}$ randomized to BIAsp 30 bid or BHI 30 bid. Unfortunately, the results here are less clear-cut since patients with type 1 or type 2 diabetes were pooled for the efficacy analyses. Of the 291 patients exposed to therapy, $104(36 \%)$ had type 1 diabetes. From a baseline $\mathrm{HbA}_{1 \mathrm{c}}$ of approximately $8.20 \%$ (8.37\% for type 1 patients, $8.09 \%$ for type 2 patients), BIAsp therapy resulted in final values of $8.14 \%$. Similarly, from a baseline $\mathrm{HbA}_{1 \mathrm{c}}$ of approximately $8.25 \%$ ( $8.38 \%$ for type 1 patients, $8.18 \%$ for type 2 patients), BHI 30 therapy resulted in final values of $8.15 \%$; this small treatment difference was not significant. Given the modest improvement in $\mathrm{HbA}_{1 \mathrm{c}}$, had type 1 and type 2 patients been analysed separately, it seems unlikely that a significant treatment difference would have been observed in patients with type 1 diabetes. ${ }^{34}$

\section{Postprandial glycemic control}

Another generalization about efficacy can be made from these trials in patients with type 1 diabetes: all report significant reductions in postprandial hyperglycemia with respect to comparator treatments. ${ }^{31-34}$ The study of 50 patients with type 1 diabetes (for a minimum of 2 years) by Hermansen et al involved a three-way crossover design. ${ }^{33}$ At each of three separate visits, patients received an injection of BIAsp 30 immediately before a standard breakfast, or BHI 30 immediately $(t=0)$ or 30 minutes before the meal $(t=-30)$. Blood samples were then taken to measure 0- to 4-hour postprandial serum glucose levels (AUC 0-4 h). Treatment ratios for AUC 0 to 4 hour were in favor of BIAsp 30; BIAsp 30/BHI $30 t=0$ : 0.77, p $<0.0001$; BIAsp 30/BHI $30 t=-30$ : $0.91, \mathrm{p}<0.05$.

Evidence from continuous therapy, however, may be more convincing. In the 24-week trial by Chen et al described above, ${ }^{32}$ which compared BIAsp 30 tid with basal-bolus therapy, mean (range) postprandial self-monitored blood glucose levels 2 hours after dinner were significantly lower with BIAsp $30(8.3$ [5.0-12.2] mmol/L) than with human insulin tid plus NPH insulin at bedtime $(9.6[6.6-18.0] \mathrm{mmol} / \mathrm{L})$; $\mathrm{p}<0.05$ between treatments. Postprandial blood glucose levels after breakfast and lunch were not significantly different between treatments. ${ }^{32}$

Good reductions in postprandial glycemia can also be achieved with twice-daily BIAsp 30, as shown in the 12-week study by Boehm et al which as mentioned earlier, pooled type 1 and type 2 patients for the efficacy analyses. ${ }^{34}$ Here, BIAsp 30 bid resulted in a mean (SEM) prandial glucose increment of $1.66(0.20) \mathrm{mmol} / \mathrm{L}$, compared with $2.34(0.19)$ $\mathrm{mmol} / \mathrm{L}$ for BHI $30 \mathrm{bid}$ (treatment difference [corrected for dose] was $-0.69 \mathrm{mmol} / \mathrm{L}, \mathrm{p}<0.01)$. These data represent the average for all three daily meals. When the meals are examined individually, it seems that treatment differences were seen after breakfast and dinner, but not after lunch, no doubt due to patients not receiving an insulin injection at lunchtime.

A similar pattern was observed in adolescent patients with type 1 diabetes. ${ }^{31}$ After 16 weeks of therapy with BIAsp 30 tid or BHI 30 at breakfast plus human insulin at lunch and dinner, a lower mean (SEM) postprandial glucose increment was achieved with the BIAsp regimen (1.34 [3.45] at baseline to 0.37 [0.41] $\mathrm{mmol} / \mathrm{L}$ at end-of-study), compared with the human insulin regimen (1.89 [3.26] at baseline to 0.77 [0.44] mmol/L at end-of-study), $\mathrm{p}<0.05$ between 
treatments (adjusted for baseline, country and last $\mathrm{HbA}_{1 \mathrm{c}}$ value).$^{31}$ Why these postprandial glucose improvements did not translate into greater reductions in $\mathrm{HbA}_{1 \mathrm{c}}$ is not clear. It may be that the study was too short for the full potential in $\mathrm{HbA}_{1 \mathrm{c}}$ reduction to be seen.

\section{Type 2 diabetes}

There are many more trials of BIAsp 30 in patients with type 2 diabetes than in patients with type 1 diabetes, reflecting the difference in the size of the populations. This allows us to examine the studies according to patient population: studies of insulin-naive patients initiating insulin with BIAsp 30, ${ }^{35-48}$ and studies of patients switching existing insulin therapy to, or intensifying with, BIAsp $30 .^{44,49-51}$

\section{Previously insulin-naive patients}

For patients failing to maintain glycemic control on OAD therapy, BIAsp 30 represents a convenient and simple option for initiating insulin treatment, as it can be injected once-daily (od) in combination with OADs. ${ }^{40-42}$ Moreover, this regimen can effectively lower $\mathrm{HbA}_{1 \mathrm{c}}$ and postprandial hyperglycemia when compared with an optimized regimen of OADs. In the 26-week trial by Bebakar et al, ${ }^{42} 191$ patients poorly controlled on one or two OADs were randomized to BIAsp 30 (0.2 U/kg/day) od before dinner in addition to their OADs, or to an optimized regimen of their existing OADs. At week 14, BIAsp 30 patients who had $\mathrm{HbA}_{1 \mathrm{c}}>8.5 \%$ or fasting plasma glucose $(\mathrm{FPG})>7 \mathrm{mmol} / \mathrm{L}$ added a further BIAsp 30 injection - at breakfast. At the end of the trial, reduction in $\mathrm{HbA}_{1 \mathrm{c}}$ was greatest in the BIAsp 30 bid group, followed by BIAsp 30 od and OADs only $(-1.34 \%,-1.24 \%$ and $-0.67 \%$, respectively; $\mathrm{p}<0.05$ for both BIAsp 30 regimens vs OADs only). Because of differences in baseline $\mathrm{HbA}_{1 \mathrm{c}}$, corresponding percentages of patients achieving target $\mathrm{HbA}_{1 \mathrm{c}}<7.0 \%$ were $24 \%, 46 \%$ and $29 \%$, respectively (baseline $\mathrm{HbA}_{1 \mathrm{c}}$ was lowest in those who received BIAsp $30 \mathrm{od}$, followed by those on OADs only). Self-measured 90-minute postbreakfast plasma glucose was also lowered by a significantly greater amount with BIAsp 30 bid relative to optimized OADs: $-2.76 \mathrm{vs}-0.92 \mathrm{mmol} / \mathrm{L}(\mathrm{p}<0.05)$; similarly, 90-minute postdinner plasma glucose was lower with BIAsp 30 od than with OADs only $(-3.41 \mathrm{vs}-1.62 \mathrm{mmol} / \mathrm{L}$; $\mathrm{p}<0.05)$. There were no significant treatment differences after lunch. ${ }^{42}$

In a smaller study of 46 insulin-naive patients with type 2 diabetes, the addition of BIAsp 30 od to an existing regimen of metformin or glimepiride, or both, resulted in all three patient groups reaching $\mathrm{HbA}_{1 \mathrm{c}}<7.0 \%$ after 6 months. ${ }^{41}$
The fact that the OAD placebo group (who received BIAsp 30 od only) also achieved this target makes the results for BIAsp 30 even more impressive.

Given these data, one may expect trials of BIAsp 30 bid to be at least as efficacious as od when compared with OAD regimens. Of course, this is not the case for published trials, since patient populations are different and OAD regimens vary from trial to trial. ${ }^{37,46,48}$ One three-arm study compared BIAsp 30 bid monotherapy with BIAsp 30 bid plus metformin, and glibenclamide plus metformin, in 341 patients poorly controlled on metformin monotherapy. ${ }^{46}$ After 16 weeks, reductions in $\mathrm{HbA}_{1 \mathrm{c}}$ appeared similar for all three treatment groups: $-1.6 \%,-1.7 \%$ and $-1.7 \%$, respectively (the difference between the BIAsp 30 regimens was statistically - but not clinically - significant). Furthermore, the mean prandial increment (average of all three meals) was also similar for the BIAsp 30 bid regimens and the OAD regimen, although when examined individually, the lunchtime increment was lower in the glibenclamide plus metformin group (treatment difference: $-1.12 \mathrm{mmol} / \mathrm{L}$ vs BIAsp monotherapy, $\mathrm{p}<0.001$, and $-0.70 \mathrm{mmol} / \mathrm{L}, \mathrm{p}=0.036$, vs BIAsp 30 plus metformin).

Perhaps one reason that the BIAsp 30 regimens in the above trial did not perform better is that dose titration was not optimal. The BIAsp 30 doses were adjusted every 1 to 7 days by 2 to $4 \mathrm{U}$, towards target blood glucose values of 5 to $8 \mathrm{mmol} / \mathrm{L}$. In the recent $\mathrm{ACTION}$ study, ${ }^{37}$ titration of the BIAsp doses was much more aggressive. Here, 200 insulinnaive patients treated with metformin plus pioglitazone during an 8-week run-in period were randomized to continue on this regimen or add BIAsp 30 bid to it. BIAsp 30 doses were adjusted according to an algorithm, with dose changes ranging from $-3 \mathrm{U}$ (if mean plasma glucose was $<4.4 \mathrm{mmol} / \mathrm{L}$ ) to $+9 \mathrm{U}$ (if mean plasma glucose was $>10.0 \mathrm{mmol} / \mathrm{L}$ over the preceding 3 days). After 34 weeks of therapy, BIAsp 30 plus OADs resulted in a significantly larger $\mathrm{HbA}_{1 \mathrm{c}}$ reduction than did metformin plus pioglitazone: $-1.5 \% \pm 1.1 \%$ vs $0.2 \% \pm 0.9 \%(\mathrm{p}<0.0001)$. Not only did more patients reach $\mathrm{HbA}_{1 \mathrm{c}}<7.0 \%$ with BIAsp 30 plus OADs (76\% vs 24\%), but the mean daily blood glucose profile was significantly lower at all eight time points with BIAsp 30/OADs compared with metformin plus pioglitazone. ${ }^{37}$ Clearly, compared with optimizing OADs, BIAsp 30 bid combination therapy can be an efficacious treatment strategy, particularly when titrated appropriately.

Commonly prescribed insulins for initiating insulin therapy in patients with type 2 diabetes include basal analogs, such as insulin glargine and detemir, and human 
premixed insulin - BHI 30. How BIAsp 30 compares with these insulins is therefore of interest. Comparative trials of insulin glargine od and BIAsp 30 bid have shown excellent reductions in $\mathrm{HbA}_{1 \mathrm{c}}$ over 6 months, ranging from $-1.6 \%$ to $2.79 \%$ for BIAsp 30 and $-1.1 \%$ to $-2.46 \%$ for insulin glargine. ${ }^{35,38}$ In the INITIATE study, ${ }^{35}$ BIAsp 30 bid plus metformin, produced a greater reduction in $\mathrm{HbA}_{1 \mathrm{c}}$ after 28 weeks than did insulin glargine od - both treatments with or without a thiazolidinedione (TZD): $-2.79 \% \pm 0.11 \%$ vs $-2.36 \% \pm 0.11 \%(\mathrm{p}<0.01)$. This corresponded to $66 \%$ and $40 \%$ of patients reaching target $\mathrm{HbA}_{1 \mathrm{c}}<7.0 \%$, respectively ( $\mathrm{p}<0.001$ ). Both insulins lowered the mean daily 8-point blood glucose profile, but the profile with BIAsp 30 was significantly lower at four time points (Figure 2). Only fasting glucose levels before breakfast were lower with insulin glargine. ${ }^{35}$

Interestingly, in a follow-up analysis of a subgroup of patients who did not receive a TZD in this study (at the time of this study TZDs were contraindicated with insulin in the EU, ${ }^{52}$ ) results were very similar, ${ }^{36}$ suggesting that insulin sensitizers do not increase the efficacy of BIAsp 30 plus metformin in this patient population.

There are very few studies comparing the efficacy of BIAsp 30 with BHI 30 in previously insulin-naive patients so generalizations cannot be made. ${ }^{39,40}$ In one of these involving 140 patients failing on metformin with or without a sulfonylurea or repaglinide, BIAsp 30 od plus metformin was trialled against BHI 30 od plus metformin, or NPH insulin plus metformin. ${ }^{40} \mathrm{HbA}_{1 \mathrm{c}}$ reductions after 12 weeks' therapy were similar between all three groups: $-1.3 \%,-1.1 \%$ and $-1.2 \%$, respectively, as were daily 8 -point blood glucose profiles. However, in a Serbian study of obese patients with type 2 diabetes, the same treatment period yielded significantly larger $\mathrm{HbA}_{1 \mathrm{c}}$ reductions for BIAsp 30 than for $\mathrm{BHI} 30$ : $-2.50 \%$ vs $-1.18 \%(\mathrm{p}<0.05$, Figure 3$) .{ }^{39}$ Furthermore, $65 \%$ of patients reached $\mathrm{HbA}_{1 \mathrm{c}}<7.0 \%$ (the ADA recommended $\operatorname{target}^{53}$ ) with BIAsp 30 compared with $30 \%$ with BHI 30 , and all time points on the 8-point daily blood glucose profile were lower. ${ }^{39}$ This was achieved with a slightly lower mean daily insulin dose for those on BIAsp 30 compared with those on BHI 30: $0.56 \mathrm{U} / \mathrm{kg}$ vs $0.58 \mathrm{U} / \mathrm{kg}$, respectively.

\section{Previously insulin-treated patients}

The above data compare favorably with those from studies in previously insulin-treated patients who transferred to BIAsp $30 .{ }^{49,51}$ In these studies, which did not focus on obese individuals, no differences in $\mathrm{HbA}_{1 \mathrm{c}}$ were found between BIAsp 30 and BHI 30, even after 2 years of therapy. ${ }^{49}$

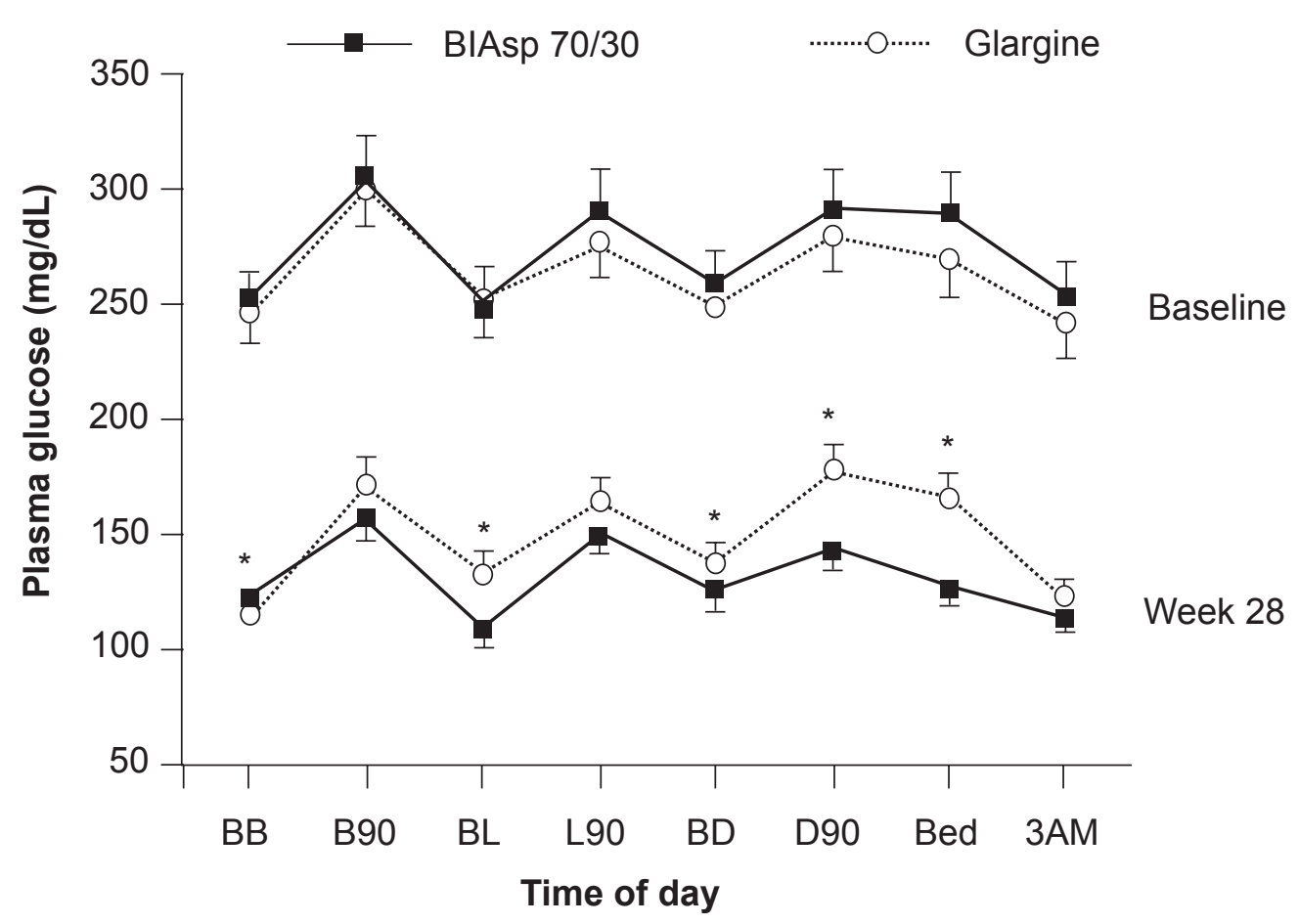

Figure 2 Daily 8-point mean blood glucose profiles after 28 weeks of treatment with BIAsp 30 bid or insulin glargine od (both in combination with metformin, with or without thiazolidinediones). Data from the INITIATE study. *P $<0.05$; errors are 2 SE. Reproduced with permission from Raskin P, Allen E, Hollander P, Lewin A, Gabbay RA, Hu P, Bode B, Garber A; INITIATE Study Group. Initiating insulin therapy in type 2 Diabetes: a comparison of biphasic and basal insulin analogs. Diabetes Care. 2005;28(2):260-265. ${ }^{35}$ Copyright (C) 2005 American Diabetes Association. 


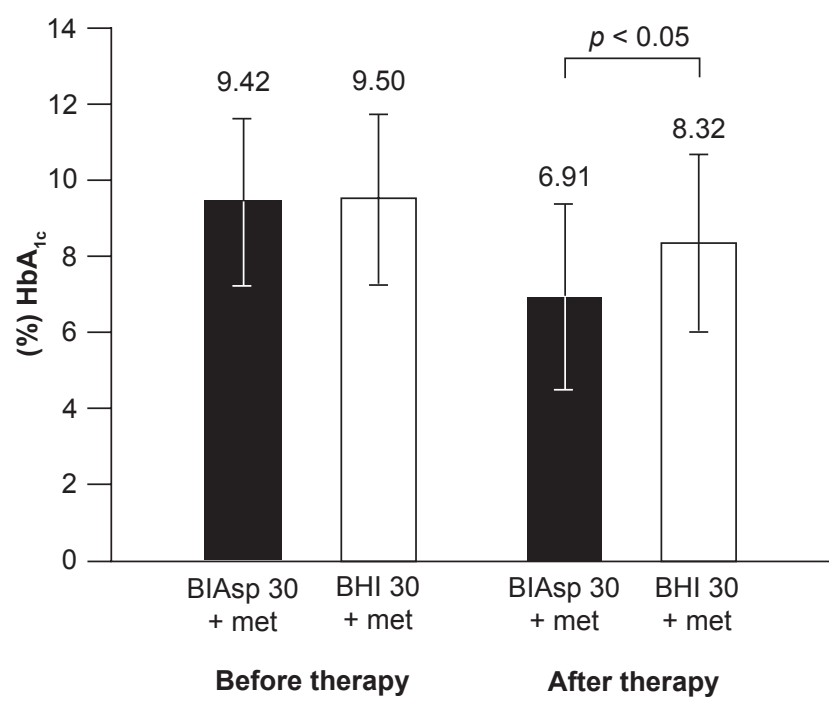

Figure 3 Significantly greater reduction in $\mathrm{HbA}_{\mathrm{Ic}}$ after 12 weeks' treatment with BIAsp 30 plus metformin than with $\mathrm{BHI} 30$ plus metformin in obese patients with type 2 diabetes. Errors are SDs. Reproduced with permission from Velojic-Golubovic M, Mikic D, Pesic M, Dimic D, Radenkovic S, Antic S. Biphasic insulin aspart 30: better glycemic control than with premixed human insulin 30 in obese patients with type 2 diabetes. J Endocrinol Invest. 2009; 32(I):23-27. ${ }^{39}$ Copyright (C) 2009 Editrice Kurtis.

One of the benefits of premixed insulin analogue therapy is the ease with which treatment can be intensified. Because of the rapid-acting nature of the soluble component of BIAsp 30 (aspart), it can be injected three-times daily (tid) if required. ${ }^{45,47,50}$ This means that an addition or change in insulin is not required when intensifying from an od or bid regimen. Convenience thus extends to the injection device patients can continue to use the same injection device, the FlexPen ${ }^{\circledR}$ (Novo Nordisk A/S, Denmark), for all injections, eliminating the possibility of mixing up insulins. ${ }^{54-56}$

Several studies have assessed the efficacy of od, bid and tid regimens of BIAsp 30 in patients with type 2 diabetes. In general, more injections enable more patients to reach glycemic targets. The $1-2-3$ trial by Garber et al ${ }^{50}$ in patients previously treated with OADs only or OADs plus basal insulin od, started 100 patients on BIAsp $30 \mathrm{od}$, and transferred all patients who did not achieve $\mathrm{HbA}_{1 \mathrm{c}} \leq 6.5 \%$ after 16 weeks to BIAsp $30 \mathrm{bid}$, and then to tid after a further 16 weeks if this target was not met. Cumulatively, by the end of the three treatment periods, od, bid and tid BIAsp 30 enabled $40 \%, 70 \%$ and $77 \%$ of patients to achieve $\mathrm{HbA}_{1 \mathrm{c}}<7.0 \% .^{50}$ Similarly, a 24-week Chinese study found that monotherapy with BIAsp 30 tid got $65.8 \%$ of previously insulin-naive patients to $\mathrm{HbA}_{1 \mathrm{c}}<7.0 \%$, compared with $51.3 \%$ with BIAsp 30 bid. ${ }^{47}$

However, a Russian trial has demonstrated that BIAsp 30 bid plus metformin can be as efficacious as BIAsp 30 tid monotherapy. In this 16-week study of 308 insulin-naive patients, final $\mathrm{HbA}_{1 \mathrm{c}}$ reductions were $-3.0 \%$ and $-2.9 \%$, respectively. Indeed, it has recently been shown that BIAsp 30 bid - even without concomitant OADs - can be almost as efficacious as basal-bolus therapy. ${ }^{44}$ Here, patients previously on OADs, with or without basal insulin od, were randomized to BIAsp 30 bid or insulin aspart tid (at mealtimes) plus basal analog insulin detemir od (or bid if required). After 6 months of therapy, $\mathrm{HbA}_{1 \mathrm{c}}$ was reduced by $-1.23 \%$ in the BIAsp 30 arm and by $-1.56 \%$ in the aspart/detemir $\operatorname{arm}(\mathrm{p}=0.0052)$, with $50 \%$ and $60 \%$ of patients reaching $\mathrm{HbA}_{1 \mathrm{c}}<7.0 \%$, respectively. Ninety-minute postprandial blood glucose levels after all three meals were also significantly lower with aspart/detemir. Interestingly, insulin-naive patients had greater $\mathrm{HbA}_{1 \mathrm{c}}$ reductions than prior insulin-users, and there was no significant treatment difference in this subgroup. ${ }^{44}$ These data suggest that starting insulin therapy with BIAsp 30 bid can be just as beneficial as starting with basal insulin and intensifying to basal-bolus therapy, with the advantage of fewer daily injections in the long-term.

\section{Safety profile and tolerability of BIAsp 30 \\ Type I diabetes}

Because of the relatively few studies of BIAsp 30 in patients with type 1 diabetes, hypoglycemia is the only adverse event reported in any detail. However, antibodies to insulin aspart - the insulin present in BIAsp 30 - have been measured in patients with type 1 and type 2 diabetes, ${ }^{57,58}$ but these were mostly not specific and cross-reactive with human insulin. ${ }^{57}$ The antibody levels decreased after 3 months of aspart therapy and were not linked to glycemic control, so this should not be an issue for most patients starting BIAsp 30 therapy.

\section{Hypoglycemia}

The occurrence of major hypoglycemia varied between studies, and does not appear to be related to trial duration. The single-injection crossover study by Hermansen et $\mathrm{al}^{33}$ described earlier, reported no major hypoglycemia in 50 patients, while 14 of the 20 major episodes (defined as requiring third-party assistance) reported with BIAsp 30 bid therapy over 12 weeks were in type 1 patients (corresponding figures were 30 of 42 episodes for BHI 30). ${ }^{34}$ However, in the 24-week crossover study by Chen et al, ${ }^{32}$ a total of 3 major events were reported by two patients with BIAsp 30 tid (1 event was reported by 1 patient in the human insulin basal-bolus group). In adolescent patients, a total of 15 major 
episodes were reported over 16 weeks -7 in the BIAsp 30 tid group (from 6 of 86 patients) and 8 in the human insulin bid/BHI 30 od group (3 of 87 patients). ${ }^{31}$

Minor hypoglycemia is more frequent than major. Due to the different ways minor hypoglycemia has been reported, it is difficult to draw straight comparisons. In the 12-week trial by Boehm et $\mathrm{al}^{34} 54 \%$ of patients reported minor events with BIAsp 30 bid (56\% with BHI 30), while the incidence was $81 \%$ in adolescent patients over 16 weeks with BIAsp 30 tid. ${ }^{31}$ Other studies reported event rate. Chen et al reported 1.1 events per patient per week for all hypoglycemia (not just minor) with BIAsp 30 tid over 12 weeks, which rose to 1.2 events per patient per week for those who added NPH insulin od to the regimen (compared with 0.7 events per patient per week for human insulin basal-bolus therapy). ${ }^{32}$ During the single-injection crossover study by Hermansen et $\mathrm{al}^{33} 16$ minor events were reported in 50 patients (18 events with BHI 30). Although comparisons between studies are difficult, it is clear that the incidence and rate of minor hypoglycemia is similar for BIAsp 30 and human insulin regimens.

\section{Weight gain}

Weight gain is often not reported in studies of type 1 diabetes, possibly because many patients are relatively young and growing, so it is not perceived as a problem.

\section{Type 2 diabetes}

\section{Adverse events}

Adverse events (AEs) associated with BIAsp 30 in patients with type 2 diabetes were commonly reported in RCTs but often not described, with incidence ranging from $20 \%{ }^{48}$ to $76 \%{ }^{36}$ of patients. Other than hypoglycemia, reported AEs with BIAsp 30 include peripheral edema (in $0 \%-9 \%$ of patients), ${ }^{37,48}$ infections and infestations (29 of 204 patients treated with BIAsp 30), ${ }^{45}$ neurological disorders (13 of 204 patients), ${ }^{45}$ gastrointestinal disorders (8 of 204 patients), ${ }^{45}$ upper respiratory tract infections $(13 \%-21 \%$ of exposed patients $),{ }^{48}$ and headache $(4 \%-10 \%) .{ }^{48}$

\section{Hypoglycemia}

Compared with type 1 diabetes, major hypoglycemia seems to be less frequent in type 2 diabetes. Indeed, several studies described in the efficacy section report no major hypoglycemia at all for BIAsp 30 or the comparator..$^{40,44,45,48}$ In those trials that do report major hypoglycemia, the frequency varies from one event associated with BIAsp 30 therapy (od or bid ${ }^{39,42}$ ) to 4 events in 102 patients. ${ }^{37}$ In the 2-year study by Boehm et al, 3 patients (5\%) on BIAsp 30 bid reported at least one major hypoglycemic event in the first year, but no events were reported during the second year. ${ }^{49}$

Minor hypoglycemia is certainly more frequent, but rates are still relatively low in some studies. In the Russian trial by Ushakova et $\mathrm{al}^{45}$ the minor hypoglycemia rate was only 0.73 events per patient-year for BIAsp 30 tid or 0.69 events per patient-year for BIAsp 30 bid plus metformin (no statistical difference). This is lower than the 8.3 events per patient-year reported by Raskin et $\mathrm{al}^{37}$ for BIAsp 30 bid plus metformin and pioglitazone, but still does not seem to be a problematic level. At the higher end of the scale, the incidence of minor hypoglycemia reported in the PREFER study was $28 \%$ for BIAsp 30 bid, ${ }^{44}$ compared with $31 \%$ for basal-bolus therapy, but $42 \%$ for BIAsp 30 bid plus metformin, compared with $14 \%$ for insulin glargine in another study. ${ }^{36}$ This may be the result of dose optimization via aggressive titration, since these were treat-to-target studies.

Possibly the most feared by patients is nocturnal hypoglycemia because it can occur during sleep. Although several trials do report the occurrence of nocturnal hypoglycemia with BIAsp 30 therapy (Liebl et $\mathrm{al}^{44}$ give an incidence of $7.4 \%$ for bid dosing over 6 months), its frequency was lower - and significantly so - in two studies. ${ }^{34,51}$ Continuous interstitial glucose monitoring over 24 hours, as well as self-monitoring of blood glucose were used by McNally et al to identify the rate of diurnal and nocturnal hypoglycemia. ${ }^{51}$ The results indicated that nocturnal hypoglycemia (or low interstitial glucose, $<3.5 \mathrm{mmol} / \mathrm{L}$ ) went largely undetected by patients, and self-reported nocturnal hypoglycemia was significantly less frequent with BIAsp 30 bid than with BHI 30 bid (1.5 vs 3.8 episodes/patient/year; $\mathrm{p}=0.002$ ).

\section{Weight gain}

Because many patients with type 2 diabetes are overweight, weight gain associated with insulin therapy may be a barrier to initiating or intensifying insulin treatment. In the trials mentioned in this review, weight gain is frequently reported with insulin treatment, including BIAsp 30. For BIAsp od, reported weight gain ranges from 0.7 (with metformin ${ }^{40}$ ) to $5.2 \mathrm{~kg}$ (monotherapy ${ }^{41}$ ). In bid or tid regimens (with or without OADs), weight gain follows a similar range: 0.7 to $5.4 \mathrm{~kg} \cdot{ }^{35,37-39,44}$ It seems sensible, therefore, that in cases where additional weight gain may pose further potential health problems, dietary and lifestyle advice given at the initiation of insulin therapy should be followed-up on a regular basis.

\section{Observational studies}

The results from RCTs described above have been confirmed in real-life patient populations by recent observational studies. ${ }^{7,59-65}$ 
These studies have been carried out in patients with type 2 diabetes - there do not appear to be equivalent studies in type 1 patients. Such studies are a valuable addition to RCTs because it is helpful for physicians to know that the results obtained in selected patients also apply to a broader population. ${ }^{66}$

In the relatively small $(n=500)$ observational study carried out in Denmark, ${ }^{59}$ and in two much larger, international studies: PRESENT ${ }^{62-65}$ and IMPROVE ${ }^{\mathrm{TM}}{ }^{7,59-61} \mathrm{HbA}_{1 \mathrm{c}}$ levels have been significantly reduced from baseline over 26 weeks of BIAsp 30 therapy. Moreover, this has been reported not only in the overall cohorts, but also in previously insulinnaive patients, those switching from other insulins (including basal insulins and human premix), and patients who had previously received no pharmaceutical therapy. ${ }^{59-62,64}$ In the largest of these studies, the IMPROVE ${ }^{\mathrm{TM}}$ study, which has reported a global cohort of 52,419 patients, the overall change in $\mathrm{HbA}_{1 \mathrm{c}}$ at end-of-study with BIAsp 30 therapy was $-2.3 \%$, with the largest reduction observed in the "no pharmaceutical therapy' subgroup $(-3.1 \%)$, followed by those that were on OADs only prestudy $(-2.1 \%)$ and insulin \pm OADs prestudy $(-2.0 \%)$. Also, as was often demonstrated in RCTs, fasting and postprandial blood glucose were significantly reduced from baseline in all prestudy therapy subgroups. ${ }^{60}$

Importantly, the IMPROVE ${ }^{\mathrm{TM}}$ study has provided useful information for physicians on how doses were adjusted when patients were transferred from other insulins to BIAsp 30. Patients who switched from human premix (BHI 30) achieved a lower final $\mathrm{HbA}_{1 \mathrm{c}}$ when they transferred their dose to BIAsp 30 unit-for-unit, rather than to a higher or lower dose (more than 10\% change in dose); moreover, more patients who switched unit-for-unit reached $\mathrm{HbA}_{1 \mathrm{c}}<7.0 \%$ (43.7\% vs $32.2 \%$ vs $38.5 \%$, respectively). ${ }^{61}$ It is noteworthy that those patients who switched to a lower or higher dose also achieved significant reductions from baseline in all glycemic parameters. When patients were transferred from a basal insulin to BIAsp 30 in the IMPROVE ${ }^{\mathrm{TM}}$ study, the prestudy dose was increased by about $50 \%$ at transfer $(0.28$ to $0.43 \mathrm{U} / \mathrm{kg})$, with a small dose increase during the 26 -week observation period (dose at final visit: $0.49 \mathrm{U} / \mathrm{kg}$ ). ${ }^{67}$

The large numbers of patients recruited in some observational studies allow them to accurately report the number and diversity of AEs, including hypoglycemia (within the limitations inherent in observational studies, such as patient recall bias). In the IMPROVE ${ }^{\mathrm{TM}}$ study, only 98 patients $(0.19 \%)$ reported serious adverse drug reactions (SADRs), and most of these were hypoglycemia. The prevalence of all other SADRs (drug hypersensitivity, injection site reaction, rash) were less than $0.005 \%$. $^{60}$
Hypoglycemia data from observational studies are more encouraging than one would expect, given the data reported in RCTs. For example, in RCTs minor hypoglycemia with BIAsp 30 is generally more frequent, ${ }^{35,38,40}$ or at best, similar to that with other insulins. ${ }^{39,49,51}$ In the PRESENT observational study, patients previously treated with insulin (with or without OAD combination therapy) reported significantly lower minor hypoglycemia 6 months after switching to BIAsp 30 in routine care (from approximately 9.0 to 2.3 events per patient-year). ${ }^{62}$ Similar results were reported in the IMPROVE ${ }^{\mathrm{TM}}$ study. ${ }^{60}$ The incidence of major hypoglycemia in BIAsp 30 observational studies was very low, consistent with results from RCTs. ${ }^{35,38,49,51,60,62}$

The weight gain associated with insulin therapy that has frequently been reported in RCTs is another issue that has not been confirmed in the wider type 2 diabetes population. ${ }^{35,41,44,50}$ Somewhat surprisingly, patients in the IMPROVE ${ }^{\mathrm{TM}}$ and PRESENT studies showed a small weight loss after 6 months therapy with BIAsp 30 ( -0.1 and $-0.32 \mathrm{~kg}$, respectively, both $\mathrm{p}<0.001) .{ }^{60,62}$ It has been suggested that dietary advice given by their physicians during the observation period may have led to healthier eating habits among patients, which may have off-set any potential weight gain due to insulin therapy. ${ }^{60}$ Whatever the reason, these large scale data are very encouraging, particularly for those patients who are in need of insulin therapy, but are worried about weight gain.

\section{Conclusion}

BIAsp 30 has pharmacological properties that make it a viable choice for initiating, or intensifying, insulin therapy in patients with type 1 or type 2 diabetes. These include a rapid-acting prandial component which is absorbed quickly and reaches higher plasma concentrations than does human insulin, and a basal component which addresses fasting insulin needs. While $\mathrm{HbA}_{1 \mathrm{c}}$ levels with BIAsp 30 in patients with type 1 diabetes are similar to those with human insulins, a benefit with regard to postprandial hyperglycemia has been demonstrated for BIAsp 30 in RCTs. Compared with basal insulins, BIAsp 30 lowers $\mathrm{HbA}_{1 \mathrm{c}}$ to a greater degree in patients with type 2 diabetes and again is particularly effective at reducing postprandial plasma glucose. While some RCTs report an increase in minor hypoglycemia with BIAsp 30 relative to basal insulin, major and nocturnal hypoglycemia are reportedly low. Furthermore, large-scale observational data support the findings from RCTs in type 2 patients. With the convenience of once- to three-times daily dosing with the same injection device - the FlexPen $^{\circledR}$ - BIAsp 30 represents a simple and effective tool for the modern management of diabetes. 


\section{Disclosures}

Paul Valensi has served as chairman to the advisory board of the IMPROVE ${ }^{\mathrm{TM}}$ study and has given lectures for Novo Nordisk.

\section{References}

1. Wild S, Roglic G, Green A, Sicree R, King H. Global prevalence of diabetes: estimates for the year 2000 and projections for 2030. Diabetes Care. 2004;27(5):1047-1053

2. DCCT/EDIC: Writing Team for the Diabetes Control and Complications Trial/Epidemiology of Diabetes Interventions and Complications Research Group. Effect of intensive therapy on the microvascular complications of type 1 diabetes mellitus. JAMA. 2002;287(19):2563-2569.

3. Bjarnegård N, Arnqvist HJ, Lindström T, Jonasson L, Jönsson A, Länne T. Long-term hyperglycemia impairs vascular smooth muscle cell function in women with type 1 diabetes mellitus. Diab Vasc Dis Res. 2009;6(1):25-31.

4. Potenza MA, Gagliardi S, Nacci C, Carratu' MR, Montagnani M. Endothelial dysfunction in diabetes: from mechanisms to therapeutic targets. Curr Med Chem. 2009;16(1):94-112.

5. American Diabetes Association. Economic costs of diabetes in the US in 2007. Diabetes Care. 2008;31(3):596-615.

6. Holmes J, McGill S, Kind P, Bottomley J, Gillam S, Murphy M. Healthrelated quality of life in type 2 diabetes (TARDIS-2). Value Health. 2000;3(Suppl 1):47-51.

7. Valensi P, Benroubi M, Borzi V, et al; IMPROVE Study Group Expert Panel. The IMPROVE study - a multinational, observational study in type 2 diabetes: baseline characteristics from eight national cohorts. Int J Clin Pract. 2008;62(11):1809-1819.

8. Vinik A. Advancing therapy in type 2 diabetes mellitus with early, comprehensive progression from oral agents to insulin therapy. Clin Ther. 2007;29 Spec No:1236-1253.

9. IDF Clinical Guidelines Task Force. Global guideline for Type 2 diabetes. Brussels: International Diabetes Federation, 2005. http://www. idf.org/webdata/docs/IDF\%20GGT2D.pdf

10. Stratton IM, Adler AI, Neil HA, et al. Association of glycemia with macrovascular and microvascular complications of type 2 diabetes (UKPDS 35): prospective observational study. BMJ. 2000;321(7258): 405-412.

11. Atkinson MA, Eisenbarth GS. Type 1 diabetes: new perspectives on disease pathogenesis and treatment. Lancet. 2001 Jul 21;358(9277):221-229.

12. Jeitler $\mathrm{K}$, Horvath $\mathrm{K}$, Berghold $\mathrm{A}$, et al. Continuous subcutaneous insulin infusion versus multiple daily insulin injections in patients with diabetes mellitus: systematic review and meta-analysis. Diabetologia. 2008;51(6):941-951.

13. Schiaffini R, Patera PI, Bizzarri C, Ciampalini P, Cappa M. Basal insulin supplementation in Type 1 diabetic children: a long-term comparative observational study between continuous subcutaneous insulin infusion and glargine insulin. J Endocrinol Invest. 2007;30(7):572-577.

14. Renard E. Intensive insulin therapy today: 'basal-bolus' using multiple daily injections or CSII? Diabetes Metab. 2005;31(4 Pt 2):4S40-4S44.

15. Harris MI. Epidemiologic studies on the pathogenesis of non-insulindependent diabetes mellitus (NIDDM). Clin Invest Med. 1995;18(4): 231-239.

16. Gerich JE. The genetic basis of type 2 diabetes mellitus: impaired insulin secretion versus impaired insulin sensitivity. Endocr Rev. 1998;19:491-503.

17. Mason CC, Hanson RL, Knowler WC. Progression to type 2 diabetes characterized by moderate then rapid glucose increases. Diabetes. 2007;56:2054-2061.

18. Lebovitz HE. Insulin secretagogues: old and new. Diabetes Reviews. 1999;7:139-153.

19. UK. Prospective Diabetes Study Group. UK prospective diabetes study 16. Overview of 6 years' therapy of type II diabetes: a progressive disease. Diabetes. 1995;44(11):1249-1258.

20. Steyn NP, Lambert EV, Tabana H. Nutrition interventions for the prevention of type 2 diabetes. Proc Nutr Soc. 2009;68(1):55-70.
21. Turner RC, Cull CA, Frighi V, Holman RR. Glycemic control with diet, sulfonylurea, metformin, or insulin in patients with type 2 diabetes mellitus: progressive requirement for multiple therapies (UKPDS 49). UK Prospective Diabetes Study (UKPDS) Group. JAMA. 1999;281(21):2005-2012.

22. Wright A, Burden ACF, Paisey RB, et al; for the UK. Prospective Diabetes Study Group. Sulfonylurea inadequacy: Efficacy of addition of insulin over 6 years in patients with type 2 diabetes in the UK. Prospective Diabetes Study (UKPDS 57). Diabetes Care. 2002;25:330-336.

23. Garber AJ, Ligthelm R, Christiansen JS, Liebl A. Premixed insulin treatment for type 2 diabetes: analogue or human? Diabetes Obes Metab. 2007;9(5):630-639.

24. Brange J, Volund A. Insulin analogs with improved pharmacokinetic profiles. Advanced Drug Delivery Reviews. 1999;35:307-335.

25. Bolli GB. Physiological insulin replacement in type 1 diabetes mellitus. Exp Clin Endocrinol Diabetes. 2001;109(Suppl 2):S317-S332.

26. Weyer C, Heise T, Heinemann L. Insulin aspart in a 30/70 premixed formulation. Pharmacodynamic properties of a rapid-acting insulin analog in stable mixture. Diabetes Care. 1997;20(10):1612-1614.

27. Jacobsen LV, Sogaard B, Riis A. Pharmacokinetics and pharmacodynamics of a premixed formulation of soluble and protamine-retarded insulin aspart. Eur J Clin Pharmacol. 2000;56:399-403.

28. McSorley PT, Bell PM, Jacobsen LV, Kristensen A, Lindholm A. Twice-daily biphasic insulin aspart 30 versus biphasic human insulin 30 : a double-blind crossover study in adults with type 2 diabetes mellitus. Clin Ther. 2002;24(4):530-539.

29. Hermansen K, Colombo M, Storgaard H, ØStergaard A, Kølendorf K, Madsbad S. Improved postprandial glycemic control with biphasic insulin aspart relative to biphasic insulin lispro and biphasic human insulin in patients with type 2 diabetes. Diabetes Care. 2002;25(5):883-888.

30. Luzio S, Dunseath G, Peter R, Pauvaday V, Owens DR. Comparison of the pharmacokinetics and pharmacodynamics of biphasic insulin aspart and insulin glargine in people with type 2 diabetes. Diabetologia . 2006;49(6):1163-1168.

31. Mortensen H, Kocova M, Teng LY, Keiding J, Bruckner I, Philotheou A. Biphasic insulin aspart vs human insulin in adolescents with type 1 diabetes on multiple daily insulin injections. Pediatr Diabetes. 2006;7(1):4-10.

32. Chen JW, Lauritzen T, Bojesen A, Christiansen JS. Multiple mealtime administration of biphasic insulin aspart 30 versus traditional basalbolus human insulin treatment in patients with type 1 diabetes. Diabetes Obes Metab. 2006;8(6):682-689.

33. Hermansen K, Vaaler S, Madsbad S, et al. Postprandial glycemic control with biphasic insulin aspart in patients with type 1 diabetes. Metabolism. 2002;51(7):896-900.

34. Boehm BO, Home PD, Behrend C, Kamp NM, Lindholm A. Premixed insulin aspart 30 vs premixed human insulin 30/70 twice daily: a randomized trial in Type 1 and Type 2 diabetic patients. Diabet Med. 2002;19(5):393-399.

35. Raskin $P$, Allen E, Hollander $P$, et al. INITIATE Study Group. Initiating insulin therapy in type 2 Diabetes: a comparison of biphasic and basal insulin analogs. Diabetes Care. 2005;28(2):260-265.

36. Raskin PR, Hollander PA, Lewin A, Gabbay RA, Bode B, Garber AJ; on behalf of the INITIATE Study Group. Basal insulin or premix analogue therapy in type 2 diabetes patients. Eur J Intern Med. 2007;18(1):56-62.

37. Raskin P, Matfin G, Schwartz SL, et al. Addition of biphasic insulin aspart 30 to optimized metformin and pioglitazone treatment of type 2 diabetes mellitus: The ACTION Study (Achieving Control Through Insulin plus Oral ageNts). Diabetes Obes Metab. 2009;11(1):27-32.

38. Kann PH, Wascher T, Zackova V, et al. Starting insulin therapy in type 2 diabetes: twice-daily biphasic insulin Aspart 30 plus metformin versus once-daily insulin glargine plus glimepiride. Exp Clin Endocrinol Diabetes. 2006;114(9):527-532.

39. Velojic-Golubovic M, Mikic D, Pesic M, Dimic D, Radenkovic S, Antic S. Biphasic insulin aspart 30: better glycemic control than with premixed human insulin 30 in obese patients with type 2 diabetes. J Endocrinol Invest. 2009;32(1):23-27. 
40. Kilo C, Mezitis N, Jain R, Mersey J, McGill J, Raskin P. Starting patients with type 2 diabetes on insulin therapy using once-daily injections of biphasic insulin aspart 70/30, biphasic human insulin 70/30, or NPH insulin in combination with metformin. $J$ Diabetes Complications. 2003;17(6):307-313.

41. Kabadi UM, Kabadi M. Comparative efficacy of glimepiride and/or metformin with insulin in type 2 diabetes. Diabetes Res Clin Pract. 2006;72(3):265-270.

42. BebakarWM, Chow CC, KadirKA, Suwanwalaikorn S, VazJA, BechOM; BIAsp-3021 study group. Adding biphasic insulin aspart 30 once or twice daily is more efficacious than optimizing oral antidiabetic treatment in patients with type 2 diabetes. Diabetes Obes Metab. 2007;9(5):724-732.

43. Home PD, Bailey CJ, Donaldson J, Chen H, Stewart MW. A double-blind randomized study comparing the effects of continuing or not continuing rosiglitazone + metformin therapy when starting insulin therapy in people with Type 2 diabetes. Diabet Med. 2007;24(6):618-625.

44. Liebl A, Prager R, Binz K, Kaiser M, Bergenstal R, Gallwitz B; PREFER Study Group. Comparison of insulin analogue regimens in people with type 2 diabetes mellitus in the PREFER Study: a randomized controlled trial. Diabetes Obes Metab. 2009;11(1):45-52.

45. Ushakova O, Sokolovskaya V, Morozova A, et al. Comparison of biphasic insulin aspart 30 given three times daily or twice daily in combination with metformin versus oral antidiabetic drugs alone in patients with poorly controlled type 2 diabetes: a 16-week, randomized, openlabel, parallel-group trial conducted in Russia. Clin Ther. 2007;29(11): 2374-2384.

46. Kvapil M, Swatko A, Hilberg C, Shestakova M. Biphasic insulin aspart 30 plus metformin: an effective combination in type 2 diabetes. Diabetes Obes Metab. 2006;8(1):39-48.

47. Yang W, Ji Q, Zhu D, et al. Biphasic insulin aspart 30 three times daily is more effective than a twice-daily regimen, without increasing hypoglycemia, in Chinese subjects with type 2 diabetes inadequately controlled on oral antidiabetes drugs. Diabetes Care. 2008;31(5):852-856.

48. Raz I, Stranks S, Filipczak R, et al. Efficacy and safety of biphasic insulin aspart 30 combined with pioglitazone in type 2 diabetes poorly controlled on glibenclamide (glyburide) monotherapy or combination therapy: an 18-week, randomized, open-label study. Clin Ther. 2005;27(9):1432-1443.

49. Boehm BO, Vaz JA, Brøndsted L, Home PD. Long-term efficacy and safety of biphasic insulin aspart in patients with type 2 diabetes. Eur $J$ Intern Med. 2004;15(8):496-502.

50. Garber AJ, Wahlen J, Wahl T, et al. Attainment of glycemic goals in type 2 diabetes with once-, twice-, or thrice-daily dosing with biphasic insulin aspart 70/30 (The 1-2-3 study). Diabetes Obes Metab. 2006;8(1):58-66.

51. McNally PG, Dean JD, Morris AD, Wilkinson PD, Compion G, Heller SR. Using continuous glucose monitoring to measure the frequency of low glucose values when using biphasic insulin aspart 30 compared with biphasic human insulin 30: a double-blind crossover study in individuals with type 2 diabetes. Diabetes Care. 2007;30(5):1044-1048.

52. Barnett AH. Summarising the use of thiazolidinediones with insulin. Br J Diab Vasc Dis. 2007;7:75-80.

53. American Diabetes Association. Standards of medical care in diabetes2009. Diabetes Care. 2009;32(Suppl 1):S13-S61.
54. Korytkowski M, Bell D, Jacobsen C, Suwannasari R; FlexPen Study Team. A multicenter, randomized, open-label, comparative, two-period crossover trial of preference, efficacy, and safety profiles of a prefilled, disposable pen and conventional vial/syringe for insulin injection in patients with type 1 or 2 diabetes mellitus. Clin Ther. 2003;25(11):2836-2848.

55. Korytkowski M, Niskanen L, Asakura T. FlexPen: addressing issues of confidence and convenience in insulin delivery. Clin Ther. 2005; 27(Suppl B):S89-S100.

56. Brunton S. Initiating insulin therapy in type 2 diabetes: benefits of insulin analogs and insulin pens. Diabetes Technol Ther. 2008;10(4):247-256.

57. Lindholm A, Jensen LB, Home PD, Raskin P, Boehm BO, Råstam J. Immune responses to insulin aspart and biphasic insulin aspart in people with type 1 and type 2 diabetes. Diabetes Care. 2002;25(5):876-882.

58. Chen JW, Frystyk J, Lauritzen T, Christiansen JS. Impact of insulin antibodies on insulin aspart pharmacokinetics and pharmacodynamics after 12-week treatment with multiple daily injections of biphasic insulin aspart 30 in patients with type 1 diabetes. Eur J Endocrinol. 2005;153(6):907-913.

59. Breum L, Almdal T, Eiken P, Lund P, Christiansen E; on behalf of the Danish BIAsp Study Group. Initiating or Switching to Biphasic Insulin Aspart 30/70 Therapy in Subjects with Type 2 Diabetes Mellitus. An Observational Study. Rev Diabet Stud. 2008;5(3):154-162.

60. Valensi P, Benroubi M, Borzi V, et al; on behalf of the IMPROVE ${ }^{\mathrm{TM}}$ Study Group Expert Panel. Initiating insulin therapy with, or switching existing insulin therapy to, biphasic insulin aspart 30/70 (NovoMix 30 ) in routine care: safety and effectiveness in patients with type 2 diabetes in the IMPROVE ${ }^{\mathrm{TM}}$ observational study. Int J Clin Pract. 2009;63(3):522-531.

61. Shah S, Benroubi M, Borzi V, et al; on behalf of the IMPROVE ${ }^{\mathrm{TM}}$ Study Group Expert Panel. Safety and effectiveness of biphasic insulin aspart 30/70 (NovoMix 30) when switching from human premix insulin in patients with type 2 diabetes: subgroup analysis from the 6-month IMPROVE ${ }^{\mathrm{TM}}$ observational study. Int J Clin Pract. 2009;63(4):574-582.

62. Khutsoane D, Sharma SK, Almustafa M, et al; PRESENT Study Group. Biphasic insulin aspart 30 treatment improves glycemic control in patients with type 2 diabetes in a clinical practice setting: experience from the PRESENT study. Diabetes Obes Metab. 2008;10(3):212-222.

63. Jang HC, Guler S, Shestakova M; PRESENT Study Group. When glycemic targets can no longer be achieved with basal insulin in type 2 diabetes, can simple intensification with a modern premixed insulin help? Results from a subanalysis of the PRESENT study. Int $J$ Clin Pract. 2008;62(7):1013-1018.

64. Shestakova M, Sharma SK, Almustafa M, et al. Transferring type 2 diabetes patients with uncontrolled glycemia from biphasic human insulin to biphasic insulin aspart 30: experiences from the PRESENT study. Curr Med Res Opin. 2007;23(12):3209-3214.

65. Sharma SK, Al-Mustafa M, Oh SJ, et al. Biphasic insulin aspart 30 treatment in patients with type 2 diabetes poorly controlled on prior diabetes treatment: results from the PRESENT study. Curr Med Res Opin. 2008;24(3):645-652.

66. Ligthelm RJ, Borzì V, Gumprecht J, Kawamori R, Wenying Y, Valensi P. Importance of observational studies in clinical practice. Clin Ther. 2007;29 Spec no:1284-1292.

67. Shah S, Ørskov C, Kawamori R. Switching to NovoMix ${ }^{\circledR} 30$ (BIAsp 30) improves glycemic control in patients with type 2 diabetes previously treated with insulin: subgroup analysis from the IMPROVE ${ }^{\mathrm{TM}}$ study. Diabetes. 2008;57(Suppl 1):A592.

Diabetes, Metabolic Syndrome and Obesity: Targets and Therapy

\section{Publish your work in this journal}

Diabetes, Metabolic Syndrome and Obesity: Targets and Therapy is an international, peer-reviewed open-access journal committed to the rapid publication of the latest laboratory and clinical findings in the fields of diabetes, metabolic syndrome and obesity research Original research, review, case reports, hypothesis formation, expert

\section{Dovepress}

opinion and commentaries are all considered for publication. The manuscript management system is completely online and includes a very quick and fair peer-review system, which is all easy to use. Visit http://www.dovepress.com/testimonials.php to read real quotes from published authors. 